\title{
SELECTION OF SUITABLE DRILLING METHOD IN RAZGAH NEPHELINE SYENITE MINE, A SYSTEMATIC APPROACH
}

\begin{abstract}
Introduction
Selection of suitable drilling method in open pit mines is one of the most important operational decisions. The drilling procedure and the selected bit type directly affect the depreciation rate of drilling rigs and the level of production costs. In general, in each mining project, before procuring blasthole drilling, the following matters must be deeply studied and answered [1]:
\end{abstract}

1. What are the blasthole parameters?

2. Which drilling method should be adopted?

3. What type of drills - diesel or electric?

4. How many blasthole drills are needed?

The selection of a suitable drilling method fundamentally depends upon the production rate, operational restrictions and the local conditions of the rock mass [1-3]. Among the mentioned factors, the parameters related to rock quality and drillability are very important. Therefore, rock drillability assessment is a core part of drilling method selection and drilling operation management.

The proper drilling method could provide higher drilling rate, longer drill bit life and less energy consumption. Therefore, the drilling method selection is known as a complex procedure which involves many geomechanical characteristics of rocks and operational parameters of the drill rig. The most important geomechanical parameters affecting drilling rate are the origin of rocks formation $[4,5]$, rock hardness [6-11], rock texture [12-14], abrasiveness [15-17], elasticity and plasticity $[9,18,19]$, unconfined compressive strength [8, 9, 18, 20], tensile strength [13], RQD and rock mass characteristics (joints and bedding) [4, 10, 21]. Therefore, for proper drilling method selection in open pit mines, the deep investigation and study of the combination of several mentioned factors which is generally called "drillability" is essential, however, it is a time consuming and data-oriented procedure.

So far, in various mining resources, a comprehensive and complete method for selecting the appropriate drilling technique in mines have not been provided clearly. Among the few available techniques for selecting a suitable drilling system, only the unconfined compressive strength (UCS) and hardness of rocks have been considered to be applied.

One of the most commonly used methods for selecting drilling methods based on UCS and drilling diameters is proposed by Jimeno et al. [3], as shown in Fig. 1. One of the biggest disadvantages of this method is the lack of attention to other physical and mechanical parameters of rocks specially the hardness and abrasiveness, which play a very important role in the drillability and selection of the drilling method and drill bit type.

As can be seen in mentioned method, the selection process neglects many important rock factors which significantly play important role in rock drillability and drilling method selection, therefore, in this paper, in order to select proper drilling method in Razgah Nepheline syenite Mine, a comprehensive stepwise study has been done on the drillability and abrasiveness of the mine ore rocks. In the following parts of paper the results of all mineralogical, mechanical, physical and field studied on the ore material of Razgah mine will be presented and the finally suitable drilling method will be recommended for this mine. 


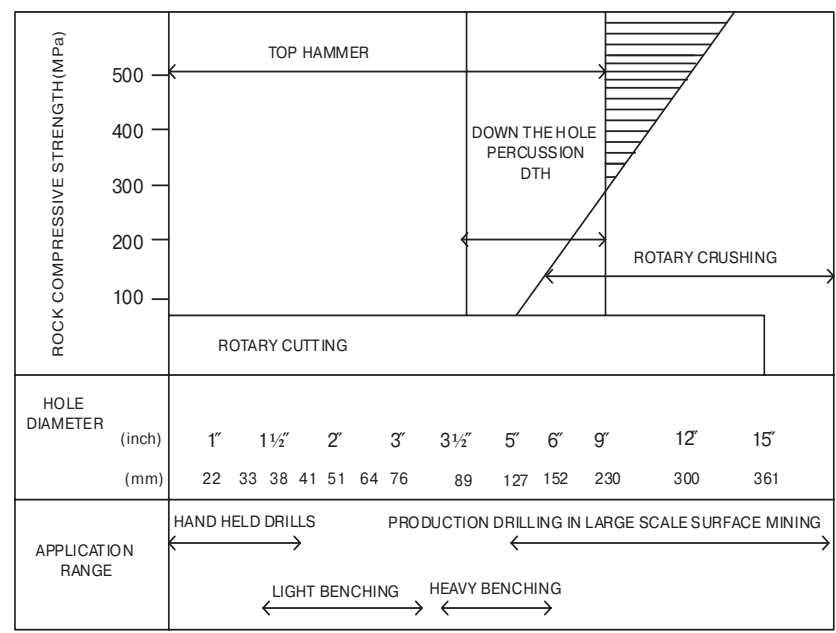

Fig. 1. Fields of application for drilling methods as function of the compressive strength of the rocks and the diameters of the blastholes [4]

\section{Laboratory studies}

Razgah is the largest Nepheline Syenite Mine in Middle East and is planned to provide 1.3 million tons of ore annually for a processing plants with total capacity of 200 thousand tons of alumina concentrate per year. This mine is currently in the pre-mining, development and technology transfer phase (by the contribution of Russian National Aluminum and Magnesium Institute (VAMI)) and in early future the production will start in this mine.

In this paper according to the results of literature review, a set of parameters were selected as the index parameters for evaluation of the drillability of Razgah mine's rock. The parameters emphasized in the researches by Thuro [2], Kahraman et al. [10], and Hoseinie et al. [17, 18], have been specially addressed. In total, the two categories of experiments were carried out on different samples collected from the mine as follows:

A. Mineralogical and textural studies: including preparation of thin sections, determination of average grain size and mineralogy composition (type and percentage of minerals).

B. Physical and mechanical properties: including determination of density, UCS, tensile strength (Brazilian test), hardness, abrasiveness (Schimazek index), modulus of elasticity and Schmidt hammer number.

In the following, the details of archived results and technical investigations of experiments are presented and explained.

Mineralogy and textural studies

In order to evaluate the drillability of any intact rock, it is essential to achieve the precise knowledge of its mineralogical characteristics and textural specifications, since very important parameters such as strength and abrasiveness is directly affected by mineralogical composition and grains' shape and size. In this research, two thin sections in a cross orientation from each sample of ore were prepared. After preparation, the taken photos from thin sections were imported to AutoCAD software for digitization and geometrical texture analysis. In the software, the four basic properties of each grain including maximum diameter, minimum diameter, area and perimeter, were calculated for all grains. Thereafter, four secondary parameters including equivalent diameter, shape factor and aspect ratio were calculated using Equation (1) to (3). Finally the results of these calculations were statistically analyzed by Easyfit software. The results of mineralogical and textural analysis and studies are presented in Fig. 2 briefly.

$$
\begin{aligned}
& D_{\text {equi }}=\sqrt{\frac{4 A_{i}}{\pi},} \\
& S F=4 \pi A_{i} / L_{p}^{2}, \\
& A R=D_{\max } / D_{\min },
\end{aligned}
$$

where, $A_{i}$ is area of grains, $L_{p}$ is perimeter of grains, $D_{\max }$ is major axis length and $D_{\text {min }}$ Minor axis length of grains. $D_{\text {equi }}$ is present equivalent diameter which means grain size, SF presents shape factor which reveals the circularity of grain cross-section and AR is aspect ratio which presents the grain elipticity [22].

Determination of physical and mechanical properties of rock

After transferring the rock samples to the laboratory, the standard test for determining the density, UCS, tensile

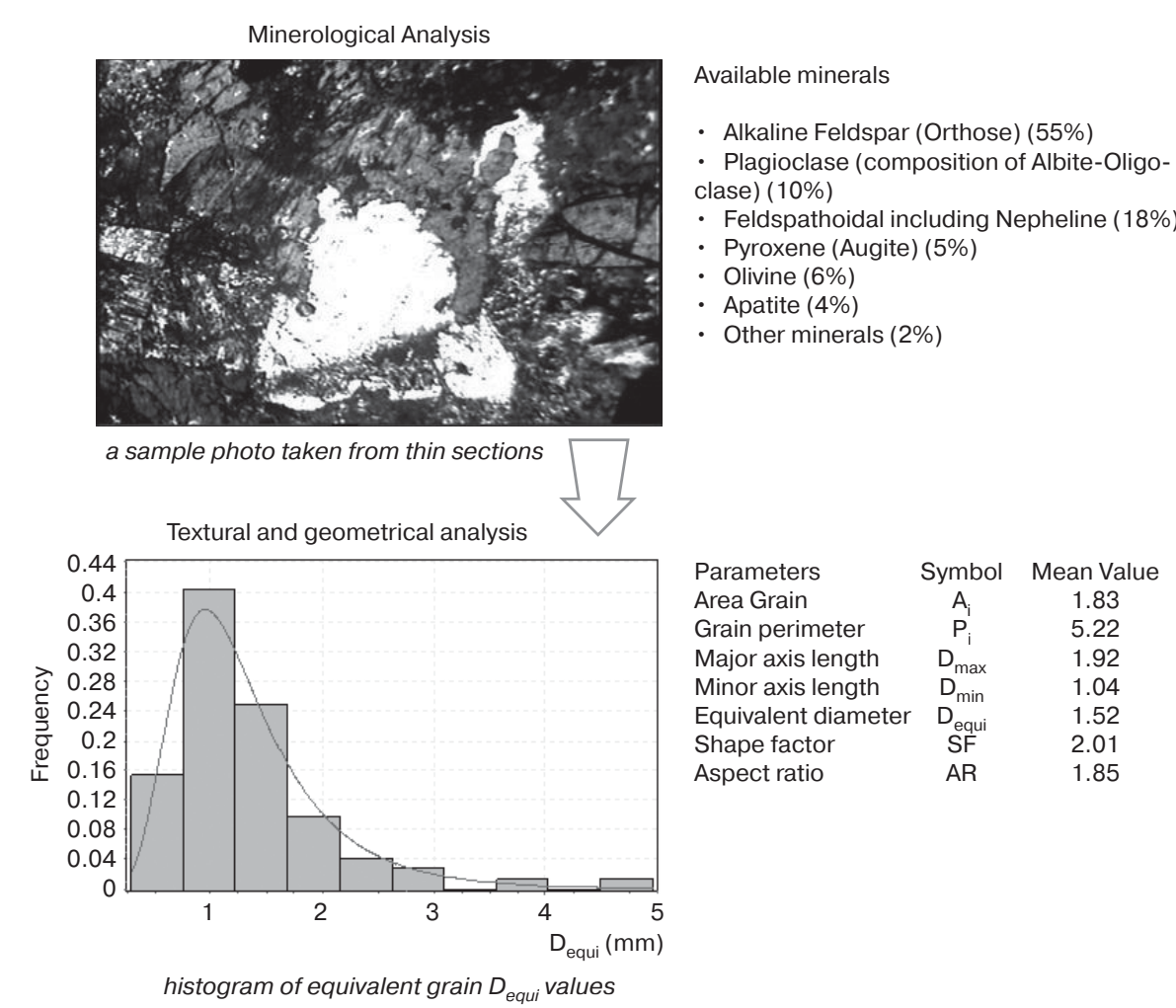

Fig. 2. The results of mineralogical and textural analysis and studies 
strength (Brazilian test), modulus of elasticity (E), Schmidt hammer hardness (S.H.H) were carried out based on the ISRM standards [23].

To calculate the rock hardness value, the weighted average of hardness of the constitutive minerals of rock was calculated using the available thin sections. Also, the rock abrasiveness was evaluated using the Schimazek abrasion index using the Equation 4 [15].

$$
\mathrm{F}=\mathrm{EqQtz} \times \varnothing \times \mathrm{BTS} / 100
$$

where EqQtz represents the percentage of equivalent quartz content, $\varnothing$ is grain size in $\mathrm{mm}$ and BTS, is the Brazilian tensile strength [15]. The percentage of equivalent quartz content of the rock samples were calculated based on Equation (5) [16].

$$
\text { EqQtz }=\sum_{i=1}^{n} A_{i} R_{i}
$$

where, $A$ indicates the percentage of minerals, $R$ is Rosiwal abrasiveness and $n$ is the number of minerals. The Rosiwal abrasiveness of the rocks is calculated based on the Mohs hardness and the relationship shown in Fig. 3.

Generally, the amount of silica or quartz content in general is very important in terms of abrasiveness of rocks. Rocks with less content of Silica, such as Dolomite or Lime, have less abrasiveness, and in opposition, more silica content such as Sandstone result in high level of abrasivity. In this paper, for getting better view of quartz content the X-Ray fluorescence (XRF) analysis were conducted on five powder samples. The XRF showed that the intact ore rock of Razgah mine contains 54.22 percent of $\mathrm{SiO}_{2}$ which is considerable amount from view point of drillability and rock abrasiveness. Table 1 shows the results of laboratory studies for determining the physical and mechanical properties of rock.

\section{Evaluation of rock drillability}

According to the results of the conducted experiments, all of the textural, mineralogical, physical and mechanical properties of the Razgah Nepheline Syenite ore rock were determined using standard laboratorial methods in order to be able to investigate the rock drillability and suitable drilling method selection. For this purpose the rock mass drillability index (RDi) and rock penetrability index (RPi) presented by Hoseinie et al. $[10,17]$ were implemented.

In the common traditional classification in drilling, the rock texture is divided into four classes based on dimensions and shape: Granular, Porphyritic, Glassy and destructive. The most specific texture in this classification is the granular in igneous rocks that is classified to five subgroups according to the grain size [24]:

1. Very coarse with grains larger than $10 \mathrm{~mm}$.

2. Coarse grains of 5 to $10 \mathrm{~mm}$.

3. Medium grains of $2-5 \mathrm{~mm}$.

4. Fine grains with grains of 0.25 to $2 \mathrm{~mm}$.

5. Very finely ground with grains smaller than $0.25 \mathrm{~mm}$.

According to the results of the thin sections, the average grains size of rock is $2.35 \mathrm{~mm}$ which is classified in mediumsize grains. With considering of RDi classification system, the rock texture is Granitoid and has got 7 scores over 15 .

In terms of UCS, Nepheline Syenite rock with $96 \mathrm{MPa}$ strength is classified in the medium-grade rocks and earns

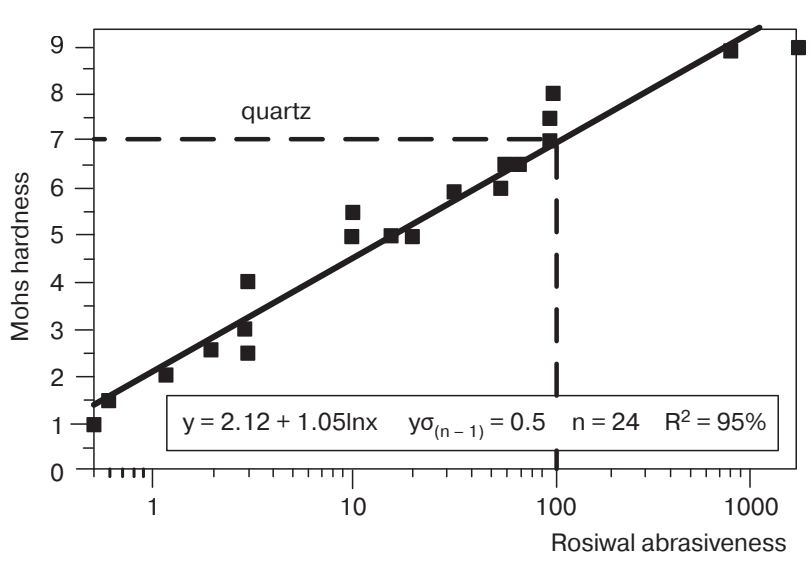

Fig. 3. Correlation between Rosiwal abrasiveness and Mohs hardness, enclosing 24 different minerals (excluding diamond) [16]

Table 1. Physical and mechanical properties of studied rock

\begin{tabular}{|l|c|}
\hline \multicolumn{1}{|c|}{ Properties, unit } & Value \\
\hline Density, gr/cm ${ }^{3}$ & 2.49 \\
\hline Uniaxial Compressive Strength, MPa & 96 \\
\hline Brazilian Tensile Strength, MPa & 4.6 \\
\hline Modulus of elasticity, GPa & 51.6 \\
\hline Schmidt hammer number & 57.2 \\
\hline Average hardness, Mohs scale & 5.85 \\
\hline Average of rock grains size, $\mathrm{mm}$ & 2.35 \\
\hline Equivalent quartz content, \% & 37.6 \\
\hline Schimazek abrasion index & 6.33 \\
\hline
\end{tabular}

11 scores over 22 in RDi classification. In the other side, the tensile strength is one of the most important rock resistance parameters. In drilling engineering, tensile strength indicates the boundary strength of grains and matrix [14]. Therefore, increasing the strength and bonding between the grain and the matrix increases the tensile strength of the rock. The bonding and high cohesion of the matrix and the grains increases the abrasiveness of the rock and ultimately reduces the drilling speed. Due to the amount of tensile strength of studied rock (4.6 MPa), it is classified in the moderate tensile strength grade.

The drillability of the rocks have an inverse correlation with the amount of elasticity. Therefore, with increasing modulus of elasticity, drilling speed decreases $[9,18]$. Based on the RPi classification, the modulus of elasticity of rocks is classified in five classes. According to the results of the experiments which present the modulus of elasticity of studied rock $51.6 \mathrm{GPa}$, it is classified as a moderate rock view point of elasticity.

Due to the amount of Schmidt hardness obtained in the laboratory, it seems that this rock has a good strength to impact. The presence of this property shows that the top hammer drill system could be faced by operational challenges due exposed damages to the drill rods and their couplings. According to microscopic studies carried out on thin sections and also the composition of this rock, it was found that the 
Table 2. Rating to five parameters of rock drillability in case study mine (considering references [14, 19])

\begin{tabular}{|l|c|c|c|c|c|}
\hline \multicolumn{1}{|c|}{ Texture } & Porous & Fragmental & Granitoid & Porphyritic & Dense \\
\hline Grain size, $\mathrm{mm}$ & - & $>5$ & $2-5$ & $0.05-1 \& 2-5$ & $0.05-1$ \\
\hline Rating & 15 & 10 & 7 & 4 & 1 \\
\hline Moh's hardness & $1-3$ & $3-4.5$ & $4.5-6$ & $6-7$ & $>7$ \\
\hline Description & Very soft- soft & Comparatively soft & Comparatively hard & Hard & Very hard \\
\hline Rating & 18 & 13 & 9 & 4 & 1 \\
\hline UCS, (MPa) & $1-25$ & $25-50$ & $50-100$ & $100-200$ & $>200$ \\
\hline Description & Very low strength & Low strength & Average strength & High strength & Very high strength \\
\hline Rating & 22 & 16 & 11 & 6 & 2 \\
\hline BTS, MPa & $<1.5$ & $1.5-3$ & $3-6$ & $6-12$ & $>12$ \\
\hline Description & Very low strength & low strength & Moderate strength & High strength & Very high strength \\
\hline Modulus of elasticity & $<10$ & $10-30$ & $30-70$ & $70-100$ & $>100$ \\
\hline Description GPa & 12 & 8 & 6 & 3 & 1 \\
\hline
\end{tabular}

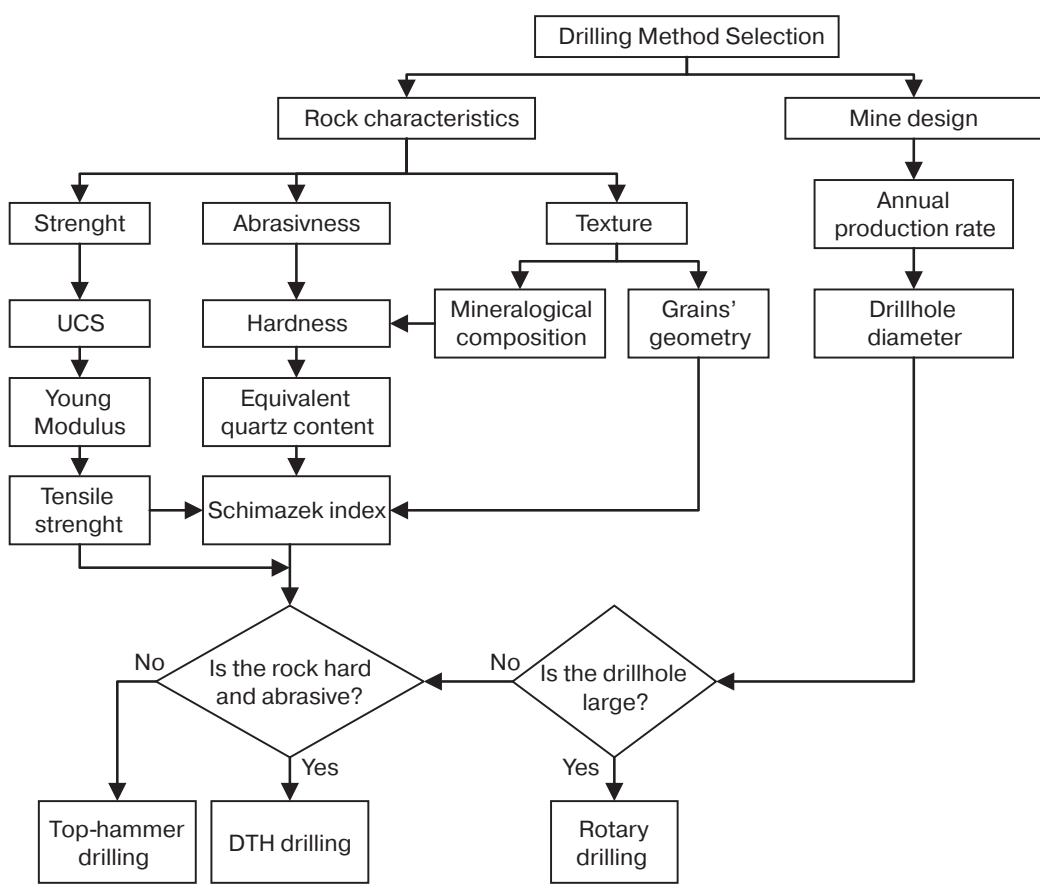

Fig. 4. Flowchart of applied approach for drilling method selection in case study mine

rock has a hardness of 5.85 in Mohs scale. In terms of hardness, with considering the RDi classification system, the studied rock is in a relatively hard rock class and gets the score of 9 over 18 (Table 2 ).

After the study of the thin sections, in order to determine the rock abrasiveness level, the equivalent quartz content of the rocks of was determined using the equation (5) and it was 37.59. The calculated equivalent quartz content means that the rock with the existing composition creates $37.59 \%$ of the abrasion created by the with $100 \%$ quartz. Also, using the equation (4), the value of the Schimazek abrasion coefficient for the Nepheline Syenite rock is calculated by 6.328 , which is very high. Hence the rock is placed in grade of abrasive rocks.

In general, according to the results of experimental studies, Razgah Nepheline Syenite rock has a moderate drillability from view point of strength parameters but classified as a low drillable rocks in terms of abrasion and hardness since it is an abrasive rock.

In the next part, the archived results from laboratorial experiments will be applied to drilling method selection in case study mine.

\section{Suitable drilling method selection}

The choice of drilling method depends largely on the operations volume, the diameter of the hole and the in-situ conditions of the rock mass. In this paper, it is tried to investigate the characteristics of intact rock from different point of view but mainly in three classes of parameters: texture, strength and abrasiveness.

The case study mine is considered as a small to moderate mine due to its annual production of 1.3 million tons of ore. Therefore, in order to achieve this level of production, there will be no need for large-diameter drilling.

Due to the medium strength and high abrasiveness of this rock, the need for an impact in drilling is obvious. So, with considering the average drilling diameters, high abrasiveness and medium mechanical characteristics, the percussive-rotation drilling system is top priority. On the other hand, considering the Schmidt hammer number obtained from the experiments, the rock reveals a relatively high dynamic hardness and cause a noticeable amount of rebound. Therefore, the down the hole (DTH) drilling method is recommended for this mine in order to prevent damage to the drilling rods and hammer device and reduce energy losses.

Since the best efficiency of DTH drilling is achieved in holes with diameters of two to six inches in hard and abrasive rocks $[1,4]$, considering the scheduled production rate in the mine, six inches diameter is proposed for extraction of rocks in Razgah Nepheline Syenite. Also, due to the abrasive nature of the case study rock in this mine, it is recommended to use the button bits in the drilling. In general, in this paper a systematic approach is implemented for drilling 
method selection which is based on rock characteristics and considers the mine production rate too. The flowchart of applied approach for drilling method selection is presented in Fig. 4.

Comparison between the result of presented approach and the drilling method selection technique presented by Jimeno et al. [4] reveals that in this method (See Figure 1) a boundary condition happens and due to rock strength and borehole diameter values, three methods of DTH, rotary crushing and rotary cutting methods could be the final choice. Nevertheless, the purposed approach method in this study clearly concludes that the DTH is the most suitable drilling system for studied rock type. It is also seen that selecting drilling method by focus on mineralogical and hardness values presents more clear result than the method which considers just UCS of rock.

\section{Conclusion}

During the drilling method selection process, correct recognition and comprehensive study of mechanical, physical and mineralogical characteristics of rocks could be very helpful and can provide better vision of rock drillability condition. However, the determination of these parameters requires the considerable amount of time and costs, nevertheless, the output can enormously reduce the operational costs through right method and bit selection.

In this paper, a wide range of studies were carried on ore rock type of Razgah Nepheline Syenite mine in order to select the suitable drilling method. A down to up approach which consisted of mineralogical studied to comprehensive strength were carried on the rock samples. The analysis reveals that according to rock RDi and RPi system, the rock is classified in moderate level of drillability. Since the production rate of the mine is designed to be 1.3 million tone, therefor, the diameter of 6 inch is selected for boreholes. In total, the studied rock is in the category of mediumstrength rocks with high abrasiveness characteristic. Taking in to account all mentioned parameters, the down the hole drilling (DTH) method is selected as suitable drilling method for the case study mine.

\section{Acknowledgements}

The financial support of Isfahan University of Technology and Center of Advanced Mining and Metallurgy (CAMM) at Lulea University of Technology is also acknowledged.

Reference

1. Gokhale B. V. Surface drilling Rotary Drilling and Blasting in Large Surface. CRC Press/Balkema, Leiden, Netherland, 2011. $744 \mathrm{p}$.

2. Thuro K. Drillability prediction: geological influences in hard rack drill and blast tunneling, International Journal of Earth Sciences. GR Geologische Rundschau. 1997. Vol. 86(2). pp. $426-438$

3. Hustrulid W. A., Kuchta M., Martin, R. K. Open Pit Mine Planning and Design. $3^{\text {rd }}$ Edition, CRC Press, 2013. 1308 p.

4. Jimeno C. L., Jimeno E. L., Carcedo F. J. A., Drilling and Blasting of Rocks. 1st Edition. Balkema, Rotterdam, 1995, 408 p.

5. Drake R. Bench drilling techniques and equipment selection manual. Ingersol-Rand, Italy 2004.

6. Wilbur L. Kuesel T. R., King E.H., Bickel J.O. (Eds). Rock tunnel engineering handbook. Melbourne, Florida: Krieger, 1982.

7. Ersoy A., Waller M. D. Prediction of drill-bit performance using multi-variable linear regression analysis. Transactions of the Institution of Mining and Metallurgy, Section A: Mining Industry, 1995. 104. pp. A101-114.

8. Serradj T. Method of assessment of rock drillability incorporating the Protodyakonov index. Transactions of the Institution of Mining and Metallurgy, Section A: Mining Industry. 1996. Vol. 105. pp. A175-A179.

9. Kahraman S., Balci C., Yazici S., Bilgin N., Prediction of the penetration rate of rotary blast hole drilling using a new drillability index. International Journal of Rock Mechanics and Mining Science. 2000. Vol. 37. pp. 729-743.

10. Hoseinie S. H., Ataei M., Osanloo M. A new classification system for evaluating rock penetrability. International Journal of Rock Mechanics and Mining Sciences. 2009. Vol. 46(8). pp. $1329-1340$.

11. Hoseinie S. H., Ataei M., Mikaiel R. Comparison of some rock hardness scales applied in drillability studies. Arabian Journal for Science and Engineering. 2012. Vol. 37(5). pp. 1451-1458.

12. Hoseinie S. H., Ataei M., Mikaiel R. Texture Effects of microfabric on drillability of rocks. Bulletin of Engineering Geology and the Environment. 2017. Vol. 78(3). pp. 1443-1449.

13. Rao K. U. M., Misra B. Principles of rock drilling. Balkema, Rotterdam, 1998.

14. Ersoy A., Waller M. D. Textural characterization of rocks. Journal of Engineering Geology. 1995. Vol. 39(3-4). pp. 123-136.

15. Singh T. N, Gupta A. R, Sain R. A. Comparative analysis of cognitive system for the prediction of drillability of rocks and wear factor. Geotechnical and Geological Engineering. 2006. Vol. 24. pp. 299-312.

16. Thuro K., PLinnge, R. J., Spam G. Drilling, Blasting and Cutting- Is it possible to qualify geological parameters relating to excavability? Proceeding of $9^{\text {th }}$ Congress of International Association of Engineering geology and the Environment. Durban, South Africa, 2002. pp. 2226-2236.

17. Hoseinie S. H., Aghababaei H., Pourrahimian Y. Development of a new classification system for assessing of rock mass drillability index (Rdi). International Journal of Rock Mechanics and Mining Sciences. 2008. Vol. 45(1). pp. 1-10.

18. Kahraman S. Rotary and percussive drilling prediction using regression analysis. International Journal of Rock Mechanics and Mining Science. 1999. Vol. 36. pp. 981-989.

19. Li X., Rupert G., Summers D. A., Santi P., Liu D. Analysis of impact hammer rebound to estimate rock drillability. Journal of Rock Mechanics \& Rock Engineering. 2000. Vol. 33(1). pp. 1-13.

20. Singh S. P., Ladouceur M., Rouhi F. Sources, implication and control of blasthole deviation. $7^{\text {th }}$ International Symposium on Mine Planning and Equipment Selection. Balkema, Rotterdam, 1998. pp. 391-397.

21. Akun M. E., Karpuz C. Drillability studies of surface-set diamond drilling in Zonguldak region sandstones from Turkey. International Journal of Rock Mechanics and Mining Science. 2005. Vol. 42. pp. 473-479.

22. Přikryl P. Assessment of rock geomechanical quality by quantitative rock fabric coefficients: limitations and possible source of misinterpretation. Engineering Geology. 2006. Vol. 87. pp. $149-162$.

23. Ulusay R., Hudson J. A. The Blue Book-The Complete ISRM Suggested Methods for Rock Characterization. Testing and Monitoring, 1974-2006. Turkish, ISRM and Turkish National Group of ISRM, 2007.

24. Osanloo M., Drilling Methods. Iran: Sadra Publication, 1998. EM 